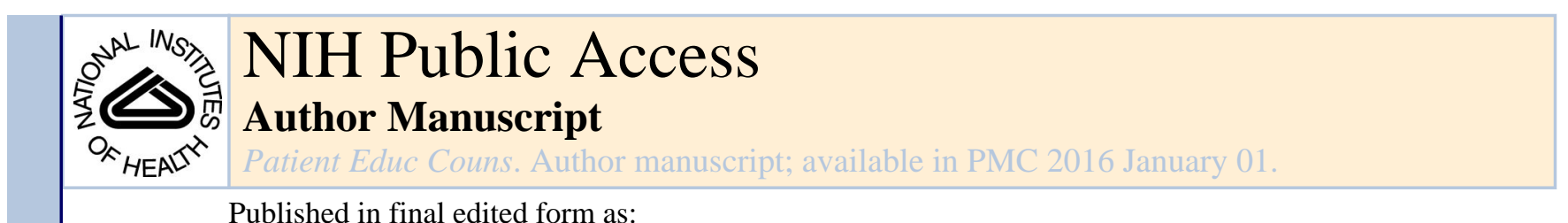

Published in final edited form as:

Patient Educ Couns. 2015 January ; 98(1): 49-54. doi:10.1016/j.pec.2014.09.014.

\title{
“Doctor, what would you do?": physicians' responses to patient inquiries about periviable delivery
}

\author{
Brownsyne Tucker Edmonds, MD, MS, MPH ${ }^{\mathrm{a}}$, Fatima McKenzie, MS ${ }^{\mathrm{a}}$, Janet E. Panoch, \\ MA ${ }^{a}$, Lucia D. Wocial, RN, PhD ${ }^{b}$, Amber E. Barnato, MD, MPH, MS ${ }^{c}$, and Richard M. Frankel, \\ $\mathrm{PhD}^{\mathrm{d}}$ \\ aDepartment of Obstetrics and Gynecology, Indiana University School of Medicine, $550 \mathrm{~N}$. \\ University Blvd., UH 2440, Indianapolis, IN 46202, USA

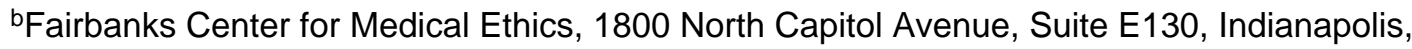 \\ Indiana 46202, USA \\ 'Division of General Internal Medicine, Department of Medicine, University of Pittsburgh School of \\ Medicine, 200 Meyran Avenue, Suite 200, Pittsburgh, PA 15213, USA \\ dMary Margaret Walther Center for Research and Education in Palliative Care, IU Simon Cancer \\ Center, 1481 W 10th Street, 11H, Indianapolis, IN 46202
}

\begin{abstract}
Objective-To qualitatively assess obstetricians' and neonatologists' responses to standardized patients (SPs) asking "What would you do?" during periviable counseling encounters.

Methods-An exploratory single-center simulation study. SPs, portraying a pregnant woman presenting with ruptured membranes at 23 weeks, were instructed to ask, "What would you do?" if presented options regarding delivery management or resuscitation. Responses were independently reviewed and classified.
\end{abstract}

Results-We identified 5 response patterns: 'Disclose' (9/28), 'Don't Know' (11/28), 'Deflect' (23/28), 'Decline' (2/28), and 'Ignore' (2/28). Most physicians utilized more than one response pattern (22/28). Physicians 'deflected' the question by: restating or offering additional medical information; answering with a question; evoking a hypothetical patient; or redirecting the SP to other sources of support. When compared with neonatologists, obstetricians (40\% vs. $15 \%)$ made personal or professional disclosures more often. Though both specialties readily acknowledged the

(C) 2014 Elsevier Ltd. All rights reserved.

Corresponding author at: Brownsyne Tucker Edmonds, MD, MS, MPH 550 N. University Blvd., UH 2440 Indianapolis, IN 46202 Phone: 317-944-1661 btuckere@iupui.edu.

fmckenzi@iupui.edu; jpanoch@iupui.edu; lwocial@iuhealth.org; barnatoae@upmc.edu; rfrankel@iupui.edu

Publisher's Disclaimer: This is a PDF file of an unedited manuscript that has been accepted for publication. As a service to our customers we are providing this early version of the manuscript. The manuscript will undergo copyediting, typesetting, and review of the resulting proof before it is published in its final citable form. Please note that during the production process errors may be discovered which could affect the content, and all legal disclaimers that apply to the journal pertain.

We confirm all personal identifiers have been removed or disguised so the persons described are not identifiable and cannot be identified through the details of the story.

Conflicts of Interest: The authors of this manuscript declare no conflicts of interest in relation to the work described here. 
importance of values in making a decision, only one physician attempted to elicit the patient's values.

Conclusion-“What would you do?" represented a missed opportunity for values elicitation. Interventions are needed to facilitate values elicitation and shared decision-making in periviable care.

Practice Implications-If physicians fail to address patients' values and goals, they lack the information needed to develop patient-centered plans of care.

\section{Introduction}

Periviable neonates bear the greatest burden of perinatal morbidity and mortality. Roughly half survive and, among survivors, up to two-thirds suffer moderate to severe neurodevelopmental disabilities.[1] Despite advances in neonatal intensive care, long-term neurodevelopmental outcomes for these infants have not improved in recent years.[2] Periviable births are emotionally and financially costly for families and the healthcare system. [3-5] Because these infants are unable to survive without ventilatory support, periviability presents parents and physicians with the unique challenge of having to make 'end-of-life decisions' at the very beginning of life. These are high-stakes, highly stressful decisions that patients have likely never faced nor contemplated. Patients rely heavily upon physicians to help them make sense of their diagnosis, prognosis, and options for care. Overcome by emotion and overwhelmed with medical information, it is not uncommon for patients to ask their physician, "Doctor, what would you do?"

A number of commentaries and editorials have offered physicians ethical frameworks to understand this question and professional techniques to navigate their responses.[6-12] Periviable counseling encounters call for shared decision-making $[13,14]$ and "What would you do" represents a pivotal question in these encounters. Few research studies have explored physicians' response patterns to this question,[15] and none have included both obstetricians' and neonatologists' responses when the question is posed at the limits of viability. Given the multispecialty nature of periviable care, it is important to understand the role each specialty plays in counseling patients. The purpose of this study was to qualitatively assess and compare obstetricians' and neonatologists' responses to standardized patients (SPs) asking: "What would you do?" while discussing delivery management and resuscitation at 23 weeks gestation.

\section{Methods}

\subsection{Study Design}

With approval from the Indiana University Institutional Review Board, we conducted an exploratory single-center simulation pilot study. The data were drawn from a larger parentstudy designed to determine the effect of patient race and insurance status on the quality and content of periviable counseling. The case depicted a 31 year-old woman presenting with preterm premature rupture of membranes (PPROM) at 23 weeks gestational age. A multidisciplinary team of physicians, including specialists from neonatology, maternal fetal medicine, and palliative care, contributed to case development. The clinical components of 
the simulation were further developed and refined in a series of pre-tests with 3 physician volunteers. We trained SPs to play the patient role based on detailed symptom and psychosocial profiles. Consistent with previous simulation work,[16] the actresses received more than 10 hours of training to ensure standardization. We instructed SPs to ask the provider, "What would you do?" if the provider presented more than one treatment option during the course of the counseling encounter. We video-recorded and later transcribed each counseling session.

\subsection{Study Population}

We recruited facutly and fellows from the Indiana University School of Medicine Department of Obstetrics and Gynecology (OB/GYN) divisions of General Obstetrics and Gynecology and Maternal Fetal Medicine and from the division of Neonatology at Riley Hospital for Children through in-person presentations at faculty meetings; e-mails to Departmental distribution lists; and calls or visits to physicians' offices. OB/GYN's practicing gynecology-only as generalists or subspecialists were excluded from eligibility; likewise, obstetricians and neonatologists who participated in case development or pilot testing were excluded. In qualitative studies, thematic saturation is customarily reached with 10-15 participants in relatively homogeneous populations [17]. Therefore, our target for recruitment was 16 OB/GYNs and 16 Neonatologists among 37 eligible OB/GYNs and 45 eligible Neonatologists. Study participation took 2 hours and included completion of simulation encounters; completion of a self-administered demographics survey; and a debriefing interview. Study participants received $\$ 100$ compensation.

\subsection{Data Analyses}

We analyzed the video recordings and transcripts using a modified grounded theory approach.[18] After viewing the video-recorded responses, we created an initial codebook that was derived inductively from physician responses to the question, "What would you do?". We then reviewed the transcripts and amended the codebook to reflect additional observations. Two trained reviewers (BTE, JP) independently coded all transcripts to ensure reliability of the coding scheme. We resolved coding discrepancies between reviewers by consensus. We used NVivo 10 to code all data and to facilitate qualitative analysis.

Codes for physician responses fell into five major categories: Disclose, Don't know, Deflect, Decline and Ignore. The 'Disclose' code applied to any direct response to the question that included a personal or professional opinion, preference, or recommendation. 'Don't know' applied if the provider responded by stating, 'I don't know' or voicing uncertainty (e.g. 'I'm not sure' or 'It's difficult to say') in their response. 'Deflect' applied to any response (other than a refusal) that failed to provide a direct answer to the SP's question. 'Decline' applied to refusals to answer the question. 'Ignore' applied to absence of a direct response, refusal, or even acknowledgement of the question. Additionally, the code, 'Values,' was applied if the provider told the SP that the decision needed to be based on the personal values, preferences or faith of a given individual or family.. Codes were not mutually exclusive, meaning that more than one code could be applied to a physician's response. Though we had initially expected respondents to fall into a simple 'did- vs did not-disclose' binary, in the 
process of coding we discovered that physician's responses were often circular and indirect. Consider the following example:

Physician X:

You know, that is a great question. I will tell you in our training they just kind of told us that we shouldn't answer that, that it's not fair to the family, but you know ... the honest answer is, I don't know ... I used to think that oh I would know and you know what happened? I got pregnant. ... I got to 23 to 24 weeks and I was terrified. I had no problems. I was very fortunate but, you know, it's different being a mom and so I can't begin to put myself into your shoes. I appreciate you asking the question. I'm not trying to avoid it. I just think really there's no right or wrong answer ... I can tell you I hope, you know what I know about ... the struggles those babies go through and ultimately what their life can be like when they survive .... I hope I would at least consider providing comfort if I could ... $[15-\mathrm{N}]$

In this physician's response, 'Don't know,' 'Values,' then 'Disclose,' codes were applied to the three underlined statements, respectively. Ultimately, we found that more than one code applied in 22 responses. Therefore, we decided to capture as many codes as applied.

\section{Results}

Sixteen obstetricians (43\%) and 15 neonatologists (33\%) participated in the study. We describe participant characteristics in Table 1. All but three encounters (28/31) included the SP's "What would you do?" prompt. In 1 of the 3 encounters, the SP failed to utilize the prompt despite being presented with more than one management option; in the other 2 , the physicians (1 neonatologist and $1 \mathrm{OB}$ ) did not provide the patient with options.

Here, we describe each category of physician response, and its subcategories, in further detail, and in Table 2, we present coding frequencies for each. Because categories were not mutually exclusive, we also present physicians' responses stratified by whether or not they made a disclosure (Table 3 ) for ease of interpretation.

\subsection{Disclose, Deflect or Decline}

Overall, physicians did not readily disclose personal perspectives to patients in response to the prompt. However, obstetricians made disclosures more often than neonatologists. Six of 15 (40\%) obstetricians provided a personal preference, opinion, or recommendation; while only $2(15 \%)$ of the neonatologists did (Table 3$)$. To illustrate, when faced with the question, one obstetrician explained:

"Me personally ... I have two kids. My husband and I had these talks because we're both [doctors], and we kinda said, you know, if this were to happen to us at this time, we would be the type of person who would just say, you know, I don't want to do anything. I don't want to intervene. But, we also know our lives and we're both very busy professionally, and I'm not sure we would have had the support and resources we needed to take care of potentially a child with very 
special needs ... And that's okay to make that choice, if that's the choice you make. [16-O].

More often, neonatologists did not give recommendations. Of the two who made disclosures, one stated that, "I would have to wait and see what my baby looks like at the time [of delivery]" [8-N]. And another explained that she honestly didn't know but hoped she would consider comfort care.

Several physicians replied with, "I don't know," either because: 'I've never faced this decision before' or 'I don't know what your values are.' For example, one neonatologist replied with: "it's hard to say because, although I've taken care of a lot of babies this early, it's never been my child, and so - sorry. . . Even if you think you know what you would do, unless you've been in that situation where it's your baby, you can't -I can't anticipate what I would actually do. [13-N]

Most frequently however, physicians chose not to provide a direct recommendation or personal preference, but instead, deflected, declined, or ignored the question. Eleven of 13 neonatologists $(85 \%)$ and 10 of 15 obstetricians $(67 \%)$ deflected the question by: 1) restating the medical information they had already presented or offering additional information to help the patient with the decision; 2) responding to the patient's question with a question; 3 ) evoking a hypothetical patient; or 4) redirecting the patient to discuss the matter with other family members, friends, clergy or social supports.

When restating information, physicians often repeated morbidity and mortality statistics, explaining, "...what I want you to understand is the numbers that I can give you . . in terms of survival... [14-N] Physicians sometimes responded to the question with a question which was oftentimes aimed at determining the patient's prior experience with prematurity, such as "Do you know of anybody who delivered someone prematurely in your family" [15-O]; or level of family support "Do you have a big support in your family?" [4-N] Although these types of questions highlight important considerations relevant to answering the "What would you do?" question, physicians provided no explanation of why the questions were being asked; nor did they subsequently respond to the original question.

Another way of deflecting the question was by evoking a hypothetical patient for whom a hypothetical recommendation was made. For instance, one participant said in response to the SP prompt, "So, we have patients who say, you know, I don't want to do anything ... And then we have patients who would do the exact opposite, and they say I want absolutely everything done." [16-O] Lastly, it was very common for providers to redirect patients to family and friends to help them make their decision, “...talk to your family and make an informed decision..." [15-O] Finally, 2 physicians (1 OB, $1 \mathrm{Neo}$ ) ignored the question altogether, and 2 obstetricians explicitly declined to answer the question.

\subsection{Values Talk vs Values Elicitation}

Almost all physicians discussed values in the course of their counseling $(23 / 28,82 \%)$. The majority $(17 / 28,61 \%)$ expressed the sentiment that it was a "personal decision" for which there were "no right answers." Some emphasized that "good parents," could make "loving decisions," choosing either option. Five (18\%) mentioned concerns about faith. However, 
only one physician $(1 / 28,4 \%)$ directly explored the patient's values. The following excerpts illustrate the distinction between 'values talk' and 'values elicitation.'

Excerpt 1: Values talk

- 4-N: [T]he position that every person is in is very different . . I'm not sure how you and your husband have been trying hard for a long period of time and . . . all your hopes and dreams are in this child ... if everything you want is [to] basically maximize what we can do, we will. But if this is going to, you know, if the outcome is really bad and poor, and this is going to be such a burden not just to you, your husband, your family, but you feel to the baby itself, then that's a decision that you guys would have to make.

Note that though this physician describes the poles of a dilemma (to resuscitate or not to resuscitate) and acknowledges that the choice depends on the parents' values, this is done rhetorically and without explicit discussion of the patient's values.

Excerpt 2: Values elicitation

SP: I don't know what to do. What would you do? What would you do?

9-O: Well, I really don't want to bias your decision, but I want to help you make this decision based on what your priorities are. You want to have.....

SP: A healthy baby. 9-O: What is "healthy" to you?

SP: Fine ... Perfect. 9-O: Perfect.

SP: I don't want all this.

9-O: Um, perfect and fine. We can never guarantee a perfect baby. Um, gosh this is difficult for me. I apologize. Hmm. Close to perfect. How close to perfect?

In excerpt 2 , the physician engages the patient in dialogue around preferences and values stating that her goal is to help the patient and her husband make the decision; not simply leaving it up to them to decide without input from the physician. Notably, this was the only encounter in which an explicit attempt at values elicitation/clarification was made in response to the prompt.

\section{Discussion and Conclusion}

\subsection{Discussion}

This pilot study explored obstetricians' and neonatologists' responses to patients' requests for advice about delivery management and resuscitation at 23 weeks gestation. After reviewing physician responses to the question, "What would you do?" we found that responses could be coded into five major categories: Disclose, Don't know, Deflect, Decline and Ignore. Most often, physicians did not disclose personal opinions or recommendations regarding periviable care. However, when compared with neonatologists, obstetricians made personal or professional disclosures more often. Within both specialties, physicians focused counseling on medical information; and though the importance of values in making a decision was readily acknowledged, patient values were rarely elicited.

Patient Educ Couns. Author manuscript; available in PMC 2016 January 01. 
Previous studies and editorials have documented reluctance among providers to disclose their personal preferences to patients.[15, 19-22] When 515 psychiatrists were randomized to different experimental counseling conditions, posing the question, "What would you do?," did not motivate providers to shift their professional recommendation and take on a more personal perspective.[20] Regarding periviable treatment recommendations, a simulation-based study of 10 neonatologists' periviable counseling behaviors, found that most declined parental requests for treatment recommendations. Notably, this was despite the fact that all of the physicians reported that they felt more than $75 \%$ certain about what should be done.[15] To these observations, we add the novel finding that obstetricians may be less reluctant than neonatologists to make personal disclosures to patients in these clinical situations. This may reflect differences in practice styles or training, as at least one neonatologist alluded to the fact that she had been trained not to answer 'that question.' Additionally, a larger proportion of the neonatologists ( $40 \%$ vs. $13 \%$ ) included in this study were fellows. It is possible that those still in training may be more cautious in how they approach counseling while those out of training may feel somewhat less constrained in their counseling practices. Another likely pertinent difference between the two physician groups is that neonatologists take care of the babies after birth, while obstetricians do not and this may impact their responses to patients' requests for advice about delivery management and resuscitation.

Previous qualitative work on periviable counseling and decision-making suggested that a provider may not disclose recommendations and/or personal opinions in an effort to respect patient autonomy.[23] Physicians may recognize that what they would choose for themselves is not what they would, nor should, recommend for their patients. Studies show that physicians tend to choose less interventional treatment for themselves than they recommend for patients.[20, 21, 24-27] Moreover, physicians' decisions for patients do not accurately reflect patients' preferences.[21] To that end, physicians may rightly avoid the paternalistic tendency to presume they know what is best. At the same time, the task of partnering with one's patients in making difficult decisions rests on the ability to effectively elicit values rather than infer or assume them. This is a concern, since values elicitation was notably absent in our encounters. While physicians readily discuss the value-laden nature of the decision, almost none took the opportunity to explicitly explore and elicit values, which the SPs were trained to share if asked. Without such information, the task of assisting patients in choosing a course of action consistent with their values relies on inference, at best, and more likely, guesswork.

Our study had important limitations. As a qualitative study performed in a single academic medical center, our findings are limited in their generalizability. For example, in our study population, physicians were disproportionately female. This may reflect the relatively young age of the cohort, and the participation of fellows. Furthermore, those physicians willing to participate in this study may differ from other physicians in important ways; perhaps they are more comfortable with communication skills or place higher value on them. If this was the case, we would expect our findings to overestimate communication skills and proficiency of providers. The simulated nature of the study also introduces the possibility of Hawthorne effects and social desirability biases. Nevertheless, our results are similar to 
other studies of physician disclosure. Moreover, the simulated nature of the encounter allows us to ensure standardization across encounters, which is a strength of the study. Finally, while some question the verisimilitude of simulation, previous work has shown that it can realistically recreate the clinical and emotional context of actual counseling encounters; [15] and in debriefing interviews, all but two of our providers found the clinical case and SP performance to be very familiar and realistic.

\subsection{Conclusion}

Periviable counseling encounters call for shared decision-making, [13, 14] and, to that end, the "What would you do" question represents a pivotal moment in these encounters. The question gives providers an opportunity to join with patients in a meaningful way that builds relationships and trust, both essential in delivering patient centered care. We do not mean to make the normative claim that physicians should disclose, for this remains a topic of debate in the ethics literature.[8, 10, 12] However, we do raise the concern that avoidance of responding directly to "What would you do" may leave patients feeling abandoned or disregarded; and thereby undermine patient-centered care. We suggest that these inquiries can create an opportunity for providers to facilitate values elicitation, which could guide decision-making with or without disclosing personal opinions. Therefore, decision support interventions and tools are needed to train obstetricians and neonatologists in values elicitation to promote shared-decision-making in periviable counseling.

\subsection{Practice Implications}

We found that, when asked for advice or recommendations regarding periviable resuscitation decisions, obstetricians and neonatologists did not respond with recommendations or disclose personal opinions, but instead, tended to reiterate medical information. And, though the importance of values in making a decision was readily acknowledged, physicians rarely asked patients about their values or goals of care. We propose that, in practice, when asked for advice or a recommendation for a value-laden decision, instead of simply commenting on the value-laden nature of the decision, physicians can inquire about patients' attitudes, fears, or preferences; then help bridge patients' preferences to a course of care that is consistent with their goals. These are hallmarks of shared decision making, which is increasingly promoted as the optimal process for the engagement of both the patient and physician in clinical decision-making.[28] If physicians fail to address values and goals, they will lack the information needed to facilitate shared decision-making and develop patient-centered plans of care; thereby resulting in suboptimal decisions which can in turn affect actions or behaviors, health outcomes, emotions, and appropriate use of health services.[29-31]

\section{Acknowledgments}

This publication was made possible in part by Grant Number KL2 TR000163 (A. Shekhar, PI) from the National Institutes of Health, National Center for Advancing Translational Sciences, Clinical and Translational Sciences Award and the Robert Wood Johnson Foundation's Amos Medical Faculty Faculty Development Program. The funders were not involved in the study design; the collection, analysis and interpretation of data; the writing of the report; or the decision to submit the article for publication. 


\section{References}

1. Kaempf JW, et al. Counseling pregnant women who may deliver extremely premature infants: medical care guidelines, family choices, and neonatal outcomes. Pediatrics. 2009; 123:1509-15. [PubMed: 19482761]

2. Hintz SR, et al. Early-childhood neurodevelopmental outcomes are not improving for infants born at $<25$ weeks' gestational age. Pediatrics. 2011; 127:62-70. [PubMed: 21187312]

3. Petrou S, et al. The impact of preterm birth on hospital inpatient admissions and costs during the first 5 years of life. Pediatrics. 2003; 112:1290-7. [PubMed: 14654599]

4. Clements KM, et al. Preterm birth-associated cost of early intervention services: an analysis by gestational age. Pediatrics. 2007; 119:e866-74. [PubMed: 17339387]

5. Gilbert WM, Nesbitt TS, Danielsen B. The cost of prematurity: quantification by gestational age and birth weight. Obstet Gynecol. 2003; 102:488-92. [PubMed: 12962929]

6. Hayes DF. What would you do if this were your ... wife, sister, mother, self? J Clin Oncol. 1991; 9:1-3. [PubMed: 1985157]

7. Kon AA. Answering the question: "Doctor, if this were your child, what would you do?". Pediatrics. 2006; 118:393-7. [PubMed: 16818588]

8. Truog R. Revisiting "Doctor, if this were your child, what would you do?". J Clin Ethics. 2003; 14:63-7. [PubMed: 14628808]

9. Truog RD. "Doctor, if this were your child, what would you do"? Pediatrics. 1999; 103:153-4. [PubMed: 9917452]

10. Halpern J. Responding to the need behind the question "Doctor, if this were your child, what would you do?". J Clin Ethics. 2003; 14:71-8. [PubMed: 14628810]

11. Ruddick W. Answering parents' questions. J Clin Ethics. 2003; 14:68-70. [PubMed: 14628809]

12. Ross LF. Why "doctor, if this were your child, what would you do?" deserves an answer. J Clin Ethics. 2003; 14:59-62. [PubMed: 12953354]

13. Griswold KJ, Fanaroff JM. An evidence-based overview of prenatal consultation with a focus on infants born at the limits of viability. Pediatrics. 2010; 125:e931-7. [PubMed: 20194275]

14. Batton DG. Clinical report--Antenatal counseling regarding resuscitation at an extremely low gestational age. Pediatrics. 2009; 124:422-7. [PubMed: 19564329]

15. Boss RD, et al. "This is a decision you have to make": using simulation to study prenatal counseling. Simul Healthc. 2012; 7:207-12. [PubMed: 22569285]

16. Barnato $\mathrm{AE}$, et al. A randomized trial of the effect of patient race on physicians' intensive care unit and life-sustaining treatment decisions for an acutely unstable elder with end-stage cancer. Crit Care Med. 2011; 39:1663-9. [PubMed: 21460710]

17. Guest G, Bunce A, Johnson L. How Many Interviews Are Enough? Field Methods. 2006; 18:59_ 82.

18. Corbin, JM.; Strauss, AL. Basics of qualitative research: techniques and procedures for developing grounded theory. 3rd ed.. SAGE Publications; Los Angeles: 2008.

19. Minkoff H, Lyerly AD. “Doctor, what would you do?”. Obstet Gynecol. 2009; 113:1137-9. [PubMed: 19384130]

20. Mendel R, et al. 'What would you do if you were me, doctor?': randomised trial of psychiatrists' personal v. professional perspectives on treatment recommendations. Br J Psychiatry. 2010; 197:441-7. [PubMed: 21119149]

21. Garcia-Retamero R, Galesic M. Doc, what would you do if you were me? On self-other discrepancies in medical decision making. J Exp Psychol Appl. 2012; 18:38-51. [PubMed: 22039766]

22. Baylis F, Downie J. Professional recommendations: disclosing facts and values. J Med Ethics. 2001; 27:20-4. [PubMed: 11233372]

23. Tucker Edmonds B, et al. Obstetric decision-making and counseling at the limits of viability. Am J Obstet Gynecol. 2012; 206:248, e1-5. [PubMed: 22381606]

24. Gardner M, Ogden J. Do GPs practice what they preach? A questionnaire study of GPs' treatments for themselves and their patients. Patient Educ Couns. 2005; 56:112-5. [PubMed: 15590231] 
25. Steinert T. Which neuroleptic would psychiatrists take for themselves or their relatives? Eur Psychiatry. 2003; 18:40-1. [PubMed: 12648897]

26. Belanger D, Moore M, Tannock I. How American oncologists treat breast cancer: an assessment of the influence of clinical trials. J Clin Oncol. 1991; 9:7-16. [PubMed: 1985172]

27. Domenighetti G, et al. Revisiting the most informed consumer of surgical services. The physicianpatient. Int J Technol Assess Health Care. 1993; 9:505-13. [PubMed: 8288426]

28. Barry MJ, Edgman-Levitan S. Shared Decision Making - The Pinnacle of Patient-Centered Care. New England Journal of Medicine. 2012; 366:780-781. [PubMed: 22375967]

29. O'Connor AM, Jacobsen MJ, Stacey D. An evidence-based approach to managing women's decisional conflict. J Obstet Gynecol Neonatal Nurs. 2002; 31:570-81.

30. Llewellyn-Thomas HA, Crump RT. Decision support for patients: values clarification and preference elicitation. Med Care Res Rev. 2013; 70:50S-79S. [PubMed: 23124615]

31. O'Connor, AM. [2014 August 7, 2014] Ottawa Decision Support Framework to Address Decisional Conflict. 2006. Available from: http://decisionaid.ohri.ca/docs/develop/ODSF.pdf 


\section{Highlights}

- Most physicians avoided providing a personal disclosure or recommendation when asked for advice

- Physicians often deflected the question by restating or offering additional medical information

- Physicians stated that the decision depended on the patient's values but failed to elicit values. 
Table 1

Study Population $(\mathrm{N}=31 ; 16 \mathrm{OB}, 15 \mathrm{Neo})$

\begin{tabular}{|c|c|c|}
\hline & Percentage & $\mathbf{N}$ \\
\hline Age & 44.0 (mean) & 30-69 (range) \\
\hline Years in Practice & 12.2 (mean) & $1.5-40$ (range) \\
\hline \multicolumn{3}{|l|}{ Specialty } \\
\hline OB/Gyn Generalist & 38.7 & 12 \\
\hline Maternal Fetal Medicine (MFM) & 6.45 & 2 \\
\hline MFM Fellow & 6.45 & 2 \\
\hline Neonatologist & 29.0 & 9 \\
\hline Neonatology Fellow & 19.4 & 6 \\
\hline \multicolumn{3}{|l|}{ Race/Ethnicity } \\
\hline White & 71.0 & 22 \\
\hline Black & 16.1 & 5 \\
\hline Asian & 9.68 & 3 \\
\hline Biracial or Multiracial & 3.23 & 1 \\
\hline \multicolumn{3}{|l|}{ Sex } \\
\hline Male & 29.0 & 9 \\
\hline Female & 71.0 & 22 \\
\hline \multicolumn{3}{|l|}{ Marital Status } \\
\hline Single, never married & 6.45 & 2 \\
\hline Married or partnered & 83.9 & 26 \\
\hline Divorced or separated & 9.68 & 3 \\
\hline \multicolumn{3}{|l|}{ Parenting } \\
\hline Yes & 77.4 & 24 \\
\hline No & 22.6 & 7 \\
\hline \multicolumn{3}{|l|}{ Religious Affiliation } \\
\hline Catholic or Protestant & 61.3 & 19 \\
\hline Jewish & 3.23 & 1 \\
\hline Hindu, Buddhist, Muslim & 12.9 & 4 \\
\hline Other & 9.68 & 3 \\
\hline None & 12.9 & 4 \\
\hline \multicolumn{3}{|l|}{ Ever Sued } \\
\hline Yes & 45.2 & 14 \\
\hline No & 51.6 & 16 \\
\hline Missing & 3.23 & 1 \\
\hline
\end{tabular}

Patient Educ Couns. Author manuscript; available in PMC 2016 January 01. 


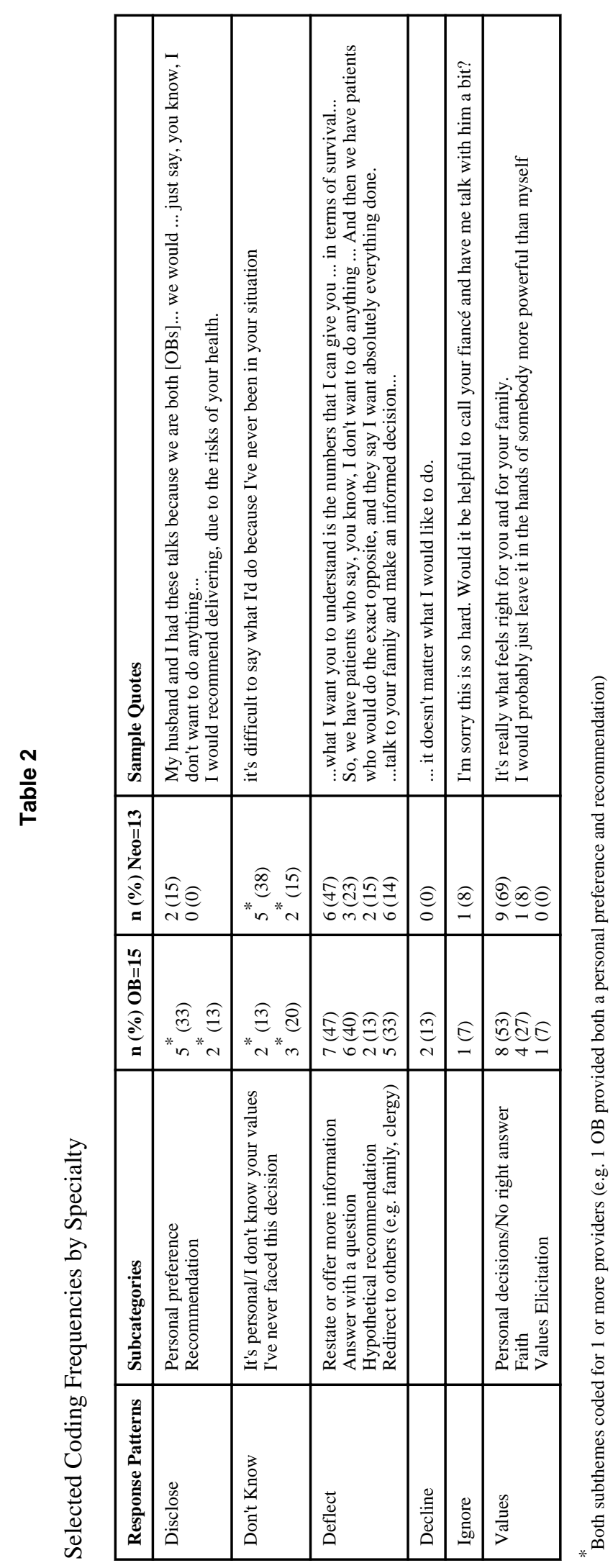

Patient Educ Couns. Author manuscript; available in PMC 2016 January 01. 


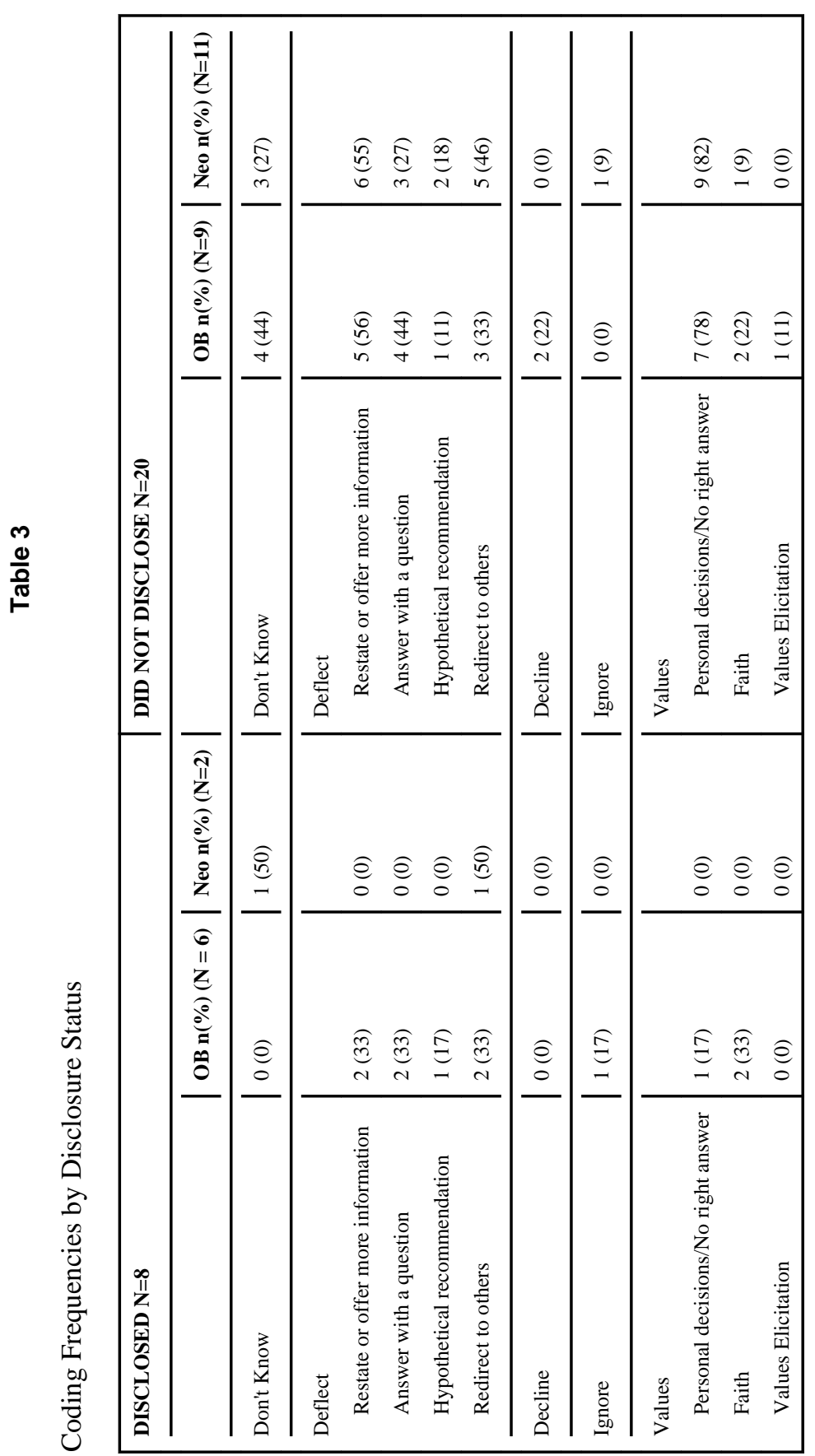

Patient Educ Couns. Author manuscript; available in PMC 2016 January 01. 